\title{
“...As significant for a relationship as taking a leak!” critical thinking and critical talking about "sex"
}

\author{
Volume 6 Issue 6 - 2017
}

\section{Opinion}

Until recent memory, sexual activity for humans and all animals was generally limited to reproduction. That is, until about 60 years ago, human sexual activity, like sex in the rest of the animal kingdom, was reproduction oriented with comparatively few isolated, but glaring and usually condemned exceptions. Sexual activity was reproductive because the female determined opportune times as she knew was related to fertilization and conception. To such purposes, all human societies had specific methods of organizing male/female relationships in a family, child oriented and child creating way. This was Nature. This was the planet. This was the animal kingdom including mankind. Sexual activity was a simple biological function for reproduction. Period. Anything else was...well, "pollution" because it was out of synchrony with planetary norms.

\section{Critical thinking}

However all human sexual activity has changed. I witnessed this and have wondered for years why and how, not the usual loud different few, but the entire human race suddenly became different from the rest of the animal kingdom in regards to sexual activity. And then it hit me! It was not that a few or even many powerful or degenerate people did not have to follow natural values, because there have always been some humans outside the normal natural loop of animal kingdom reproduction as the main style of sexuality. This was different because, I suddenly realized that, almost the entire human species has replaced natural sex (reproductive) with non-reproductive genital activity, and, therefore, reproduction has been removed from general human evolution. Amazing. And how was this done? By: Contraception and Abortion!--which rendered defunct the natural, and up to now accepted, environmentally sound, planetary purpose of sexual activity. Thereby, any natural enthusiasm for babies and children was replaced by the reflex gasp spasm of "sex" now meaning nothing more than momentary exhilarating ejaculation-orgasm without the normal and usual natural reproductive consequences. "Sex" was no longer reproductive; no longer uniting; no longer intimate; no longer spiritual; no longer tender; no longer loving; it became meaningless mechanics with the significance of "hello" and "goodbye" - or, infra, "as significant for a relationship as taking a leak!"

Coinciding with contraception and abortion in destroying natural planetary environmentally sound sex for the human species was Sex Education For Children - an unnatural imposition of adulthood in gross violation of the Right to Childhood and destructive of the well established "latency phase" of child development wherein a child learns during formative years how to learn and to work without the stresses and craziness of adulthood. Sex ed fails most because preadults are notoriously immature and incompetent: They burn things with their cigarettes and ashes are everywhere. They cannot handle alcohol usually puking and falling. They drive terribly as insurance rates recognize. They cannot find their homework or get it done on time. They cannot make or keep a schedule without many reminders.

\author{
Samuel A Nigro M.D \\ Retired, Assistant Clinical Professor Psychiatry, Case Western \\ Reserve University School of Medicine, USA
}

Correspondence: Dr. Samuel A Nigro M.D., Retired,Assistant Clinical Professor Psychiatry, Case Western Reserve University School of Medicine, 2517 Guilford Road, Cleveland Heights, Ohio 44I I8, USA, Tel 216 932-0575, Email sam@docnigro.com

Received: March 16, 2016 | Published: February 06, 2017

Their manners are terrible. They cannot save any money spending it on junk. They play computer games thinking it is real living. They join gangs and cliques following gurus. They use pot thinking it makes them smart. They think television and movies are real information. They need to be told when to go to bed. They complain about everything from doing the dishes to carrying out the trash. They aren't allowed to vote because they do not know what country they are living in. They cry when their feelings are hurt but a moment later can be very cruel. They think they are entitled to everything and do not know what gratitude is. Being "monkey see, monkey do" jellyfish, they believe and imitate celebrities and each other. They cannot even keep their rooms clean nor do their own laundry. And pick up after themselves, forget about it. Actually, they are supposed to learn how to do all this during latency but sex ed, as if they can be competent with contraception when they are incompetent with everything else, muddles it all. As with most everything, youths will be incompetent with abstinence programs too. But by imposing adulthood, sex ed is not protection from but an invitation to participate in a culture promoting sex. For pre-adults, sex-ed is a forced unnatural imposed stimulation and therefore a form of rape (It would be sex harassment if imposed on adults at work) by perverted adults themselves gratuitously excited about exciting children. Boys especially are injured by all this, and thus, without latency, they often defend themselves from a hostile culture by inordinate investment in games et cetera. Overall, boys become poor students, poor workers, and can become selfishly overly aggressive including sex, i.e. they become sub rosa rapists modeling themselves after their sex ed teachers; and since sex for them began as boys with other boys and adults, they become NAMBLA members or porno addicts when adults (Anyone confused about that is a foolYes! Sex ed leads to child sex and pornography.).

Because men (males and females) are suggestible creatures of habit prone to imitate and do all seen and heard, humans have become overwhelmed to compulsion by the uninhibited reflex gasp spasm of repetitive squirt/moan-slime/squeal ejaculation-orgasm ("orgasm"how great it is to be a man-by the atavistic physiologic imitation of male ejaculation by women i.e. the ultimate penis envy-ersatz 
manhood: slime/squeal supercedes child-orientation and the woman is now more male than female in regards to planetary norms). The once reproductive reflex has become a 60 second reflex gasp spasm...a meaningless, useless, dignityless, non-functional, unnatural, antievolutionary, polluting, trivial event desideratum with or even without another person.

With the appearance of contraception, abortion and sex ed for children, human "sex" is no longer sex as it had always been (and still is for the rest of the animal kingdom). For humans sex is just squirt/moan or slime/squeal...get it over with one way or another... anywhere, everywhere...who cares? It is the spasm that counts. All that matters in the universe now is whoopee squirt/moan-slime/squeal day in or day out. Basically, human sex and the reproductive system have been removed by humans for themselves from what it is for the rest of the planet, consistent with man's, sometimes divine and other times demonic, ability to escape from nature because he is above nature. Basically, it seems that if humans can pollute, we will. And it is now sexual pollution because human sexual behavior is no longer "real sex" as it has been and still is for the rest of the animal kingdom. Mankind is out of synchrony with the planet again - this time with universal absolute pathological denial! Regardless, by contraception, abortion and sex education, mankind has psychologically and physiologically exterminated his reproductive system. The penis has become a pee squirt spasm plunger and the vagina has become a spasm death tunnel, neither doing what designed for in nature. And when anyone complains about man causing the extinction of creatures, tell them to look in the mirror and wake up, because they are complaining about the wrong creature being made extinct. And also tell them that man has never been more unplanetary, and therefore anti-environmental, than by contemporary sexual norms.

Regardless, non-sex "sex" has taken on a life of its own in violation of the animal kingdom mode as well as Natural Law. So what has human "sex" really become? Removed from marriage and any other social unitary process consistent with the rest of the animal kingdom's use of sexuality for reproduction and unition, the human genital organs are now not only anatomically but almost totally functionally related to excretion. That is, except for what is necessary for ejaculation and orgasm, all genital and reproductive organs could disappear, and probably will if evolution is true and the human species lasts that long. Today, at bottom (pun intended), sex cannot be differentiated from excretion because "sex" has become nothing more than a "relief" function.

To be accurate, contemporary genital activity for humans should be called "sexcretion" or "squime" (a neologism made by combining "squirt" and "slime" in respective physiologic sexual activity for men and women) or "moeal" (another neologism combining "moan" and "squeal," respectively for man and woman again). Today, sexcretion or squime or moeal are relief functions with the emission of secretions for that relief-and that is it! A squirt/moan-slime/squeal contest is imposed on us all. For males, it is who can squirt (make that "hold back" squirting) the longest and who can moan the loudest; and, for females, it is who can slime the most often and squeal the loudest; such is contemporary sex for the human species. If other animals were taught to do that, it would be animal cruelty and equivalent to teaching bulimia to the other animals. This is pathology and pollution.

Given current technological trends, there will soon be available innumerable self stimulating gadgets designed to titillate and stimulate squirt/moan-slime/squeal sexcretory genital activity whenever desired. There will be squirt/moan-slime/squeal stimulators able to duplicate activity of the penises of Bill Clinton (with Oval Office desk top unique techniques!), Hugh Heffner, Bill Moyers, Jesse Jackson, and others willing to provide the genital action templates. There will also be gadgets duplicating the mouth and tongue movements of Hillary Clinton, Barbara Streisand, and Walter Cronkite. Available will be the fingers, hands, mouths et cetera of Mohammed Ali, Michael Jackson, and Ruth Bader Ginsberg. One will be able to obtain both male and female genital duplicators of a race horse, a sheep, a great dane, and a lion or lioness, and the animal of your choice. There will be vaginal duplicators for the likes of Madonna, Brittney Spears, Katie Couric, and Barbara Walters. There will be mouth movement and anus duplicators of homosexuals from Democratic Representative Barney Frankes, diver Greg Louganis, Oprah and road hog Rosie O'Donnell. All celebrities will likely make their squirt/moan-slime/ squeal sexcretion gadgetry available to further enhance their images of squirt-squeal (nee' sexual) prowess. No doubt, everybody will have their favorite sexcretor, squimer or moaeler in their homes. And no longer will there interest or need for enhancing enlarging drugs i.e., at last, at last, size will not matter... as if it ever did in the animal kingdom. Hotels will no longer bother with television porn only but make available the squime moael sexcretion gadget of popular genital best celebrities or politicians-remote self-stimulating play gadgets, condoms for hygiene, will be available to use with your favorite celebrity in action on the television screen. And political campaigns will never be the same! No doubt, few people will ever leave their rooms, homes or hotels. The world will likely be at peace with everyone just squirt/moaning-slime/squealing away all day and all night and not even bothering anybody else ever...no partner necessary ... a paradise for "anything goes" liberals, the anti-human fake press \& media, and anti-evolutionary Planned Parenthood. Finally, at a more deep psychological level, each human's personal identity will now be primarily determined by their sexcretory preference and they can consider their gadgets or whatever to be their spouses, laws to make it so soon to follow!

Thusly, true independence will be obtained and no one will ever need a partner or even people at all any longer. Age will not matter either...Sex researchers have always masturbated infants...so who will object? Who will want to take time away from their sexcretor? Let everyone have the right to huff and puff away any way all ways... a Spasm Shoot Clause hidden in the Second Amendment of the U.S. Constitution. The population problem will be solved and school closings will be as common throughout the world as in France and Italy. A choice of how one wants to use the sexcretion squime moael reflex will be each individual's right and rightfully influenced by the suggestibility advertising spasm experts in the press and media who will extoll their own versions eager to sell their own squime-moael gadgets. Not only will gender be truly meaningless but so will human identity and one's own being...call it the ultimate equality: everybody is squirt-slime sexcreting like everybody else! Reproduction will be (is!) as passé as raising a family. And no one will have to bother with the difficulties of family life either! Free and last? And the only thing that matters is "Was it good?"

Or just maybe this simple reflex ruling all is absurd...and, yes, pollution. Regardless, the contraception-abortion sex ed mentality has brought this to fruition, and the divine surprises and evolutionary mysteries for mankind are over. Thank you, Planned Parenthood, sex educators and all the dehumanizing know-it-all frauds and the loud uncivilizing unreliable self-righteous sanctimonious press and media untouchables eager to sell junk from themselves to junk ideas. Squirtmoan/slime-squeal determines one's main identity, one's inspiration and one's life? Some dream, and not to be forgotten: "Without a dream, people perish." 
Really, there has to be more and so-called "sex" has to minimized more than exploited because all it has given the world contemporarily is AIDs, STDs, genital preoccupation, cervical cancer, breast cancer, empty homes, closed schools, little to none social bonding, isolated young adults who can engage only in extimacy (sexcretion) and not intimacy, pervasive selfishness, perverted self esteem, loss of capacity for virtue, chronic depression, and "the body is a toy." Au fond, what passes for "sex" today is neither love nor freedom but the anti-spiritual biological confining straitjacket of secular atheism.

\section{Critical Talking}

Some reject what has happened and are looking for a method to defuse and rightly diminish the hypnotizing brain washing deconditioning which seduces almost all exposed to the flood of ejaculation/orgasm titillations and impositions for global universal sexcretion. The most cogent recent explanatory protest is the full issue of the Linacre Quarterly, November 2007, Volume 74, Number 4-a mandatory read for anyone interested in what has happened to human sexuality--That entire issue is "the high road"! Unfortunately, I do not think it will defuse the excitement from the sex promoters who overwhelm the will in spite of the intellect.

In contrast, what you are reading from me in this article is "the low road" necessary because the degrading must be at the level of the enticing, otherwise the porno people win the suggestibility contest by default. Unfortunately for man, almost everything seen or heard is contagious and we tend to be readily deconditioned so as to be able to imitate all we see from concentration camps to running around naked to buying whatever is attractively packaged and surrounded by glitzy music. Something must be done to those who do nasty things to each other and impose it on the rest of us. Indeed, the sex promoters are relying, as the evil doers proclaimed in The Heart of Darkness, that the good guys will be too good to do what needs to be done. No way. Maybe "shock appeal" can work for good for a change. We should dish it out. They will not like it anymore than traditional people like what the sex perverts are doing...they won't stop....and neither will we.

In what follows, I propose words and phrases which may help defuse the hypnotizing stimulating addicting qualities of squirt/moanslime/squeal sexcretion reflex gasp spasm. The words will biologize what is seen and offered. That is, openly and grossly articulating the biology of sexcretion will help mock it to amusement rather than leaving unattacked the "me too," "you too," "monkey see, monkey do" suggestions and advertising for reflex gasp spasm. This is "the low road," necessary because sexcretion must be dealt with at its own degraded level. It is enticing and enthralling that its own indecency must be used against itself. There is a purpose to dirty minded schoolboy nastiness: the protection and buffering against premature genital excitement. Needless to write, whatever is said and done to neutralize reflex gasp spasm mentality must be surrounded by positive education, intriguing academic challenges, sports, work, and service to others - all this to replace and sublimate the tsunami of sex filled garbage and pollution from the press and media.

All need help to deal with the flooding of our culture with seductive hypnotizing sexual imagery and suggestions. All need to become immune to the suggestibility and imitations offered to gullible everybodies by so-called sex educators ("perverts" really) and the secular press and media, and all who use "sex" to sell junk food, junk clothes, junk ideas, and junk whatever. Indeed, contemporary cultures tend to be "suggestibility contests" wherein sex (sic) stimulating images are used to attract attention and create excitement to get their polluting unnatural ideas across. The haunting "monkey see, monkey do" impact of the seductive images and the enticing music must be neutralized. My contention is that words and phrases are needed to reduce the contagiousness of the grotesque anti-natural use and appeal of the flood of sexcretion enticements. Paradoxically, odds are that the porno acceptors and porno promoters will not like this... and porno rejectors won't either. But it must be done if those most affected are to be immunized against the culture of disgust. Perhaps it would help to say that I am just updating The Catcher in the Rye-liberals loved it for breaking vocabulary new ground, and they cannot object to what I offer.

The recommended words and phrases are not appropriate for use for normal people committed to the dignified, wonderful and sacred natural sex ways of reproduction and unition who deserve dignity, class and sophistication. Marital sex is like the beauty and sacredness of Rome, while non-marital sex and pornography are like the sewers of Bagdad. Thus, the recommended words and phrases are for only those who have removed human sex from its natural marital reproductive mode as described supra. The recommended words and phrases are for those individuals who exploit their genitals and bodies in some way seeking only the squirt/moan-slime/squeal reflex pleasure spasm which is, once again, not real sex when removed from reproduction or unition. The goal for the offered words and phrases is to reduce the excitement associated with exposures to genital behavior. These words and phrases should reduce such to biological amusement removing the seductive imitative suggestibility impact of what genital promoters desire.

\section{Critical Talk: Words to Reduce Genital Exploitation:}

"Dirty words" are used all the time in movies and no one cares. But use them in real life about people who deserve to have them used, and the free speech liberals go bonkers in protest. Regardless, use these words as recommended without apologies about those who exhibit themselves and carry on publicly to titillate and exploit others.

BREASTS - Call them "milk-cancer-sweat-fat-pontoon-hanginguseless-chest-glands". That is a mouthful, no pun intended. In that sequence, whenever anyone is inappropriate or exploiting breasts, say, "Those sure are big milk-cancer-sweat-fat-pontoon-chest-glands, aren't they?"

BUTTOCKS - Call them "bowel movement protectors," "BM Protectors," or "anus protectors." Whenever anyone is wiggling their callipygian ass around say, "She sure likes to protect her BM hole... her anus...or (what the hell) her asshole, doesn't she?" Then add: "I wonder if she wipes front to back or back to front"... ask her if you get the chance-yell it out.

CLEAVAGE - Call it "front mooning" or "front ass crack." Say, "Are you mooning me? Do you have an asshole in front too?"

PROMISCUOUS FEMALE - Call them a "bowling alley vagina." "She is so genital she has a bowling alley vagina - everybody rolls their balls down her."

FEMALE PUBIC or VAGINAL EXPOSURE - Call it a "three hole cunt" - one hole for urine, one for blood and one for feces. When exposed, say, "You can see her three hole cunt - one is for urine, one is for blood and one is for feces... 'cunt' stands for 'cesspool under neath them' and that is her all right"-Using "cunt" is fine now because it is part of the liberal public lexicon ever since audiences were led to chant it out loud in the play Vagina Monologues (which should be Three Hole Cunt Monologues) well accepted by liberal wackos everywhere 
EXPOSED PENIS - Call it "a pee squirt spasm plunger parade baton" - "That guy sure has a big pee squirt spasm plunger parade baton - he needs a drum to beat with it."

EJACULATION/ORGASM - Call it "squirt-moan-slime-squeal." Always say, "All that genital stuff on television (on the internet, in the movies) makes you want to squirt-moan/slime-squeal doesn't it? Do you fart when it happens to you? A lot of people do because they gulp air when they carry on like that."

PORNOGRAPHY - Call it "a bunch of neighborhood dogs" - Say, "I haven't seen pornography pollution like that since our neighborhood dogs were licking each other's butts, balls, genitals and humping each other-but at least the dogs were trying to reproduce which is what sex is really for."

NON-MARITAL INTERCOURSE - Call it "Fxxking" - that is the word to use. "There goes the fxxking fart contest - pornography people fart a lot." - "When you see this kind of fxxking, think fart because that is what they are doing - that isn't love." And "If it is outside marriage, it is called fxxking - those doing it are called fxxkers." The use of this word derisively degrades and removes any positive aspects to non-marital sexual activity.

NON-MARITAL GENITAL ACTIVITY - Is a useless compulsive non-sexual chewing gum-like body rubbing, squirt/slime 90 second moan/squeal spasm seeking which is valueless except for selfish gasping relief and grandiose imagined non-beingness, almost all of which is pure entropy but, nevertheless, easily becoming more habitual than cigarettes or cocaine.

“...AS SIGNIFICANT FOR A RELATIONSHIP AS TAKING A LEAK!"-A universal phrase for criticizing non-marital sexual activity. It was first stated by a Jamaican man in my office telling me why he was going back home to find a woman to marry. He said, "American women are really something. You can always get a hand job, a blow job, or a quick screw. It is as significant for our relationship as taking a leak."

Obviously no one deserves to hear these demonic words except those degrading themselves by or those prone to be deconditioned or seduced by exhibitionistic unnatural extramarital sexual activity or by other unplanetary paraphilias. The pollution of sexcretion itself must be overtly, blandly, matter-of-factly degraded to minimize its exciting impact which can lead to imitation. The recommended words and phrases will help reestablish the right to childhood, i.e., where there is no sexualization or genitalization expected or allowed until the child's sex hormones are in control. This "dirty minded schoolboy" style of put-down is a healthy defensive maneuver for children in the latency age especially such that sexual stimulation does not intrude deeply into their mental lives (The "latency age" is the well established psychological developmental age of childhood wherein sexual matters should be minimized until sex hormones are in control. The latency age makes most sex educators to be pedophiles.).
The basic theme is that the most all pre-adolescent children should hear about sex is that "sex is for making babies after you are married" or, if exposed to exploitation, they should hear the "critical talk" proposed supra. It will change and strengthen their chemistry. That is all they need to know. That is all they should be subjected to. Anything else is a violation of latency and a violation of the right to childhood (Read my Childhood Manifesto).

Finally, Suggestibility Prevention Programs are needed in all grades (see my "And Satan Turned Into An Angel of Light") with promulgation of THE TEN SUGGESTIBILITY DEFEATING HINTS:

1. DO NOT BE SO IMPRESSIONABLE OR SUGGESTIBLE.

2. DO NOT BE SO GULLIBLE ABOUT SIMPLE BIOLOGICAL FUNCTIONS.

3. DO NOT BE A "MONKEY SEE, MONKEY DO COPYCAT"YOU ARE NOT A MONKEY.

4. CELEBRITIES ARE FAKES. IT TAKES THEM HOURS TO LOOK THAT WAY, AND THEY GET PAID TO CARRY ON LIKE THAT.

5. BELIEVE NOTHING ON TELEVISION, IN MOVIES, ON THE INTERNET, OR IN NEWSPAPERS WITHOUT TWO CONFIRMATIONS FROM SOMEONE YOU TRUST.

6. DO NOT BELIEVE OR DO ANYTHING EXCEPT WHAT IT TRUE, ONE, GOOD AND BEAUTIFUL NO MATTER WHAT IS DONE OR BELIEVED BY OTHERS.

7. THE SPIRIT LIFE MEANS THAT YOU ARE WHAT YOU THINK-SO THINK MATTER, IDENTITY, TRUTH, ONENESS, GOOD AND BEAUTY, AND ALL WILL BE WELL.

8. IN THE LONG RUN, YOU WILL GET, FOR ETERNITY IN HEAVEN, PURGATORY, OR HELL, WHATEVER YOU HAVE THOUGHT AND DONE...SO THINK AND DO WHAT IS TRUE, ONE, GOOD AND BEAUTIFUL.

9. BOYCOTT ALL ANTI-SPIRITUAL DEHUMANIZING DEGRADING ANTI-NATURE GLITZY NONSENSE FROM THE LOUD UNCIVILIZING UNRELIABLE SELFRIGHTEOUS SANCITIMONIOUS PRESS AND MEDIA UNTOUCHABLES.

10. STAY A KID AS LONG AS YOU CAN. ADULTHOOD IS A LOT OF WORK. YOU ARE NOT MISSING A THING.

\section{Acknowledgments}

None.

\section{Conflicts of Interest}

None. 